\title{
Lumen
}

Selected Proceedings from the Canadian Society for Eighteenth-Century Studies

\section{Molly Canons: The Role of Slang and Text in the Formation of Queer Eighteenth-Century Culture}

\section{Jes Battis}

Volume 36, 2017

URI : https://id.erudit.org/iderudit/1037858ar

DOI : https://doi.org/10.7202/1037858ar

Aller au sommaire du numéro

Éditeur(s)

Canadian Society for Eighteenth-Century Studies / Société canadienne d'étude du dix-huitième siècle

ISSN

1209-3696 (imprimé)

1927-8284 (numérique)

Découvrir la revue

Citer cet article

Battis, J. (2017). Molly Canons: The Role of Slang and Text in the Formation of Queer Eighteenth-Century Culture. Lumen, 36, 129-141.

https://doi.org/10.7202/1037858ar 


\title{
Molly Canons: The Role of Slang and Text in the Formation of Queer Eighteenth-Century Culture
}

\author{
JES BATTis \\ University of Regina
}

This discussion will focus on the role of slang and canting languages in the development of queer subcultures during the long eighteenth century. In particular, it will address the subcultural vocabulary of London mollies, a queer lexicon which emerged from the criminal slang known as thieves' cant. While previous criticism has offered brief discussions of how the mollies borrowed from criminal slang, I want to examine the complexity of their oral tradition, which points to a number of overlapping communities, both criminal and working-class. In reviewing work done by Rictor Norton, Sally O'Driscoll, and Stephen Shapiro, this article will expand upon a conversation that has mostly treated linguistic factors as secondary to the development of molly culture, rather than as a force which defined their lines of affiliation and performative practices. It will also trace productive uses of molly slang within texts which may have been designed for a molly reading public, analyzing how particular terms gained strength at the intersection between private speech and public print. This was more than an ad hoc language; rather, it was an alphabet of survival, allowing them to cohere as a community while creating a linguistic afterlife which would preserve their language and values.

A canon of critical work already exists on the mollies as an urban phenomenon in eighteenth-century London, but existing discussions tend to treat the insider language of the mollies as a blunt tool for avoiding detection. Alternatively, "mollying cant" is read by some 
critics as a wholesale fabrication, created by hostile writers to amplify the effeminacy of the mollies, or a purpose-built argot designed to "baffle" authorities. Paul Baker is the only writer to explicitly discuss the relationship between mollying cant and the later dialect of Polari, which was enthusiastically taken up by a specific community of British gay men between 1940 and 1970. Baker's linguistic study, Polari: The Lost Language of Gay Men, offers a compelling but too brief discussion of this linguistic legacy. Most treatments of molly culture dwell upon the performative aspects of their community, and relatively recent work by Sally O'Driscoll and Tanya Cassidy has analyzed the mollies in relation to class politics, but there are few discussions of the molly language as an overlapping cultural development. This discussion attempts to fill in these gaps by analyzing the emergence of a linguistic community that fused prison slang, actors' "parlyaree," and global dialects which represented London's changing social landscape. I argue that the mollies were at the center of this dialectical flourishing, and rather than simply repurposing cant terms, they braided sympathetic cultures together with hostile epithets in order to create a new queer language.

In order to track the language of the mollies, we must examine their development as a culture, which is itself contested. There are a number of interrelated dates which saw molly house raids and organized persecution, but there is no agreed-upon point of emergence. The historian Alan Bray discusses a community of class-disparate men who held secret gatherings, and whose activities were discovered by the Societies for the Reformation of Manners during the first decade of the eighteenth century. ${ }^{1}$ In fact, persecution of mollies began as early as 1698 , when the Societies launched their first sting operation to arrest Captain Edward Rigby. His trial inspired ballads and broadsides, along with the re-printing of past sodomy trials. The mollies emerged, in part, from this galaxy of textual insult. Randolph Trumbach notes that "there are descriptions of molly houses in 1709, 1714, and 1729," dates which correspond roughly to pogroms and sting-operations carried out by the SRF.' Several pamphlets about the mollies focus on their devel-

1. Alan Bray, Homosexuality in Renaissance England (New York: Columbia University Press, 1982).

2. Randolph Trumbach, "London," in Queer Sites: Gay Urban Histories Since 160o. Ed. David Higgs. (London: Routledge, 1999), 91. 
opment of an unsettling hybrid language, a mixture of slang and exaggerated female performance, but the molly lexicon emerges at a unique intersection between criminality and sexuality. Rictor Norton observes that "the dialect of the molly subculture may have had much in common with the Rogue's lexicon." In particular, there is a cultural sympathy between the words moll and molly, both of which come from the sex-trade.

Slang terms employed by the mollies - such as "buss" for kiss, "cull" for go-between (or fool), and "caudle" for anal sex - were often creatively adapted from canting language. The term cant or canting emerged from the Latin verb cantare, meaning "to sing." It was attributed to the singsong tones of beggars and vagabonds who worked the notorious London district of Alsatia. Maurizio Gotti describes this jargon as "containing terms commonly used by beggars and thieves to denote the essential elements connected with their mischievous way of living." ${ }^{\prime \prime}$ Canting was a shared vocabulary among thieves, prostitutes, and mollies (who often ran in the same circles). John McMullan notes that the language thrived in "Pennyrent or low lodging houses... [where] quarters were minute, pushed together, and linked by narrow passageways." 5 This mirrors Alan Bray's description of the "unsanity warrens" that included molly houses, such as Saffron Hill. Canting dictionaries are replete with creative terms for sexuality, given that they emerged from networks of prostitution and illegal enterprise. Scant criticism has remarked on the durable linguistic relationships between mollies, sex-workers, and demi-criminals (such as distillers of unlicensed gin) who shared close quarters and often had to protect each other. Writers such as Henry Fielding depicted antagonism between sex-workers and mollies, particularly in Amelia, but this was a convenient print gesture which sought to write over the alliances that formed between overlapping communities. Numerous trials from the Old Bailey reveal a shaky but enduring network between sex-workers and mollies, some of whom were also involved in the sex trade.

3. Rictor Norton, Mother Clap's Molly House: The Gay Subculture in England 1700-1830 (London: GMP, 1992), 103.

4. Maurizio Gotti, The Language of Thieves and Vagabonds (Berlin: De Gruyter, 2012), 16 .

5. John McMullan, The Canting Crew (New Brunswick, NJ: Rutgers, 1984), 109. 
By connecting these marginalized communities through a linguistic thread, I want to argue that molly cant was more than slang. It was an evolving dialect, tempered by its relationship with various, implicated speech communities. And it survived well into the twentieth century, mutating in unexpected and productive ways, forming an oral tradition still used by LGBTQ communities. If we don't attend to the significance of this slang as a foundational factor within the lives of the mollies, we risk denying the broader significance of alternative, anti-oppressive language within queer communities today. Randolph Trumbach has noted that "many of the popular terms once used for female prostitutes were subsequently used to categorize effeminate men," ${ }^{6}$ but this comment doesn't clarify how the mollies themselves may have adopted this term, or how the linguistic relationship between molly sexuality and prostitution could have emerged from sympathy rather than antipathy. Molly was in fact a uniquely flexible term noun, verb, and adjective - whose precise meaning was dependent upon context and tone. Trumbach also argues that "the molly houses were able to guard themselves against the unsuspecting visitor, and it is clear that one could enter them only if guided by a sodomite." ${ }^{\text { B }}$ But members of the SRF were also able to impersonate mollies, or to gain admittance by objectifying themselves as "trade." What likely secured access wasn't necessarily a performance, but rather, a command of the molly language, since other credentials could be fabricated. Fluency was the key, and this was a shaping force within the consolidation of molly culture, just as it remains an influence on communication within queer communities today.

What, precisely, does molly mean? How was it used both in oral and textual practice, and how might its various slippages have informed the culture to which it referred? The following section of this discussion will trace the linguistic origins of this term, not necessarily agreed upon. Ned Ward, a self-styled reporter, is likely the first to put the term molly into circulation in his 1709 History of London Clubs. ${ }^{8}$ It's unclear whether the mollies had previously used this term. It appears in records from the Old Bailey as early as 1726 , in the Ordinary's account of

6. Trumbach, 92 .

7. Trumbach, 101.

8. Edward Ward, The Second Part of the London Clubs (London: J. Dutton, 1709). 
Thomas Wright's indictment. The term has a unique flexibility: it's used as a noun to describe Molly Houses, but also as an adjective, describing an unnamed informant as "a blowing-up Mollying bitch." The cant adjective "blowing" is attached to sex-workers as early as 1673 , when "blower" is glossed as "wench" in Thomas Head's Canting Academy. ${ }^{10}$ In the 1745 trial record of Richard Manning, molly appears both as a noun ("So, Molly") and as a verb ("I never mollied you"), proving its versatility, as well as its complexity. ${ }^{11}$ The mollies represent themselves within the textual contact point between community and criminality, borrowing and repurposing slang terms in order to create a flexible argot. Sally O'Driscoll notes that criminal pamphlets and court trials are the only type of evidence which tell us anything direct about them: "Thus there is no alternative but to try to read the records of mollies with an ear for the nuance of the rhetoric."12

In 1728 , molly appears for the first time in a document explicitly linked to the canting tradition. In the "Genuine Narrative" attributed to the criminal James Dalton, the word molly is used to describe a number of individuals within the club. ${ }^{13}$ The document includes a brief canting dictionary, which does not offer molly as a term. However, it does define the term mag as a sodomite. The absence of molly from this dictionary suggests that it was already widespread enough that it required no further clarification. Mag also shares linguistic similarities with madge and margery, two slang terms which will gain further currency in the nineteenth century as markers for same-sex prostitution. The term reappears as late as 1811 , and far from being a textual antique, it continues to circulate within discussions of sodomy in the Regency period. We might think of molly-margery as a lexical continuum from

9. The Proceedings of the Old Bailey: Thomas Wright, April 20, 1726. http://www. oldbaileyonline.org/browse.jsp?id=t17260420-67\&div=t17260420-67\&terms=mollying \#highlight

10. Thomas Head, The Canting Academy. 1673. Early English Books Online.

11. Qtd. in Netta Goldsmith, "London's Homosexuals in the Eighteenth Century: Rhetoric versus Practice," in Queer People: Negotiations and Expressions of Homosexuality, 1700-180o. Ed. Chris Mounsey and Caroline Gonda (Lewisburg: Bucknell University, 2007), 183-94, 189.

12. Sally O'Driscoll, “The Molly and the Fop: Untangling Effeminacy in the Eighteenth Century," in Developments in the Histories of Sexualities, ed. Chris Mounsey (Lewisburg, PA: Bucknell University Press, 2013), 156.

13. James Dalton, A Genuine Narrative of all the Street Robberies Committed since October by James Dalton. 1728. Eighteenth Century Collections Online. 
which a number of flexible subjects emerge, taking on the social nuances and slang evolutions of each distinct era. ${ }^{14}$

The mollies are often described as belonging to a "cultural moment" which lasts from 1698-1732, after which the public scandal dies down. O'Driscoll states that, after the 1730 , "the word molly disappears, along with any evidence of the molly himself." ${ }^{15}$ From this perspective, the roughly three decades during which mollies were an object of polemic seems to be a discretely bounded event, running parallel to anxieties around urban culture and the dissolution of the libertine model. However, Rictor Norton observes that "by the beginning of the nineteenth century the Molly subculture had become the Margery subculture... [and] by the end of the nineteenth century, Mary-Ann had become the accepted term." 16 The mollies survived through transformative vocabulary, and just as Norton traces their evolution forward in time, it is possible to go back as well, before Ned Ward's 1709 citation, and discover a ghostly presence within the language of cant. As early as 1567 , Thomas Harman's dictionary defines the word margery as a hen, with the dual meaning of voluble woman. ${ }^{17}$ By 1608 , Thomas Dekker includes the word Margery-prater as a hen or scold. ${ }^{18}$ These earlier terms will eventually take the place of molly, though that word never vanishes. We still use it today in the form of mollycoddle. But this word also plays tricks on us. Coddle comes from the Latin cauda, which means tail. As an insult, it is firmly of the molly era.

Before the publication of canting dictionaries, these terms emerged from the oral tradition known as "Parlyaree," spoken by early-modern performers and criminals. The ties between theatrical communities and criminal enclaves were both flexible and enduring, since many performers straddled the divide between both worlds. Over time,

14. Variations on Mary appear earlier in Spain as markers of homosexuality. The epithet maricón, still used in contemporary Spanish, derives from marica, which in turn derives from Mary as a proper name. Cristian Berco discusses this lexical evolution in his study on sexuality and the inquisition. See Sexual Hierarchies, Public Status: Men, Sodomy, and Society in Spain's Golden Age (Toronto: University of Toronto, 2007).

15. O'Driscoll, "The Molly and the Fop," 147.

16. Norton, Mother Clap's Molly House, 105.

17. Harman, Thomas. A caueat for commen cursetors vvlgarely called uagabones. 1567. Early English Books Online. 29.

18. Dekker, Thomas. Lanthorne and candle-light. 1608. Early English Books Online. 
Parlyaree came to be known as Polari, a dialect spoken by gay men in Britain during the second world war. The historian Paul Baker suggests that the word drag probably comes from the Polari phrase bona drag, which means, "nice outfit." ${ }^{19}$ While searching through canting dictionaries for uses of the word molly, I noted an instance of the word drag in a manual from 1699, published under the pseudonym B.E. Gent. ${ }^{20}$ Drag is defined therein as "a Fox's tail," which suggests both aesthetic and performance: not only the drag of the tail, but also its transformation into a muff or stole, which might have completed a drag outfit. The drag of the fox tail eventually becomes the drag of the gown.

Within the broader lexicon of thieves' cant, the mollies also employed a specialized vocabulary, designed to strengthen community ties while baffling outsiders. Alan Bray describes this as "a language tailored to fit the experiences and characteristics of the sexual life of a molly house. In origin, they were usually heterosexual terms turned to new and ironic applications." 21 Words like 'chapel' and 'marry' were slyly invoked to describe sex between men. Bray notes that most of these marriages only lasted for a night. There were, however, exceptions. "Occasionally," says Norton, "marrying went beyond a single wedding night... and was celebrated with at least some of the formality of the heterosexual equivalent." 22 He cites the marriage of two mollies, a blacksmith and a butcher, which is described in Dalton's Genuine Narrative. ${ }^{23}$

Thus far, I have argued that the mollies emerged from cultural traditions both oral and written, making use of canting language for their own purposes, while also participating in criminal society to the extent that it offered protection and secrecy. They were real people who also found living space within fiction, and who adapted a crosscultural slang that was lively and organic, even as it was being frozen into text by outsider-produced dictionaries. I want to conclude by examining what relationship the molly language had to reading, and how their speech was echoed in print publications. This essay has

19. Baker, Polari: The Lost Language of Gay Men, 81.

20. B. E. Gent, A New Dictionary of the Terms Ancient and Modern of the Canting Crew. 1699. Early English Books Online.

21. Bray, Homosexuality in Renaissance England, 86.

22. Ibid., 100.

23. Dalton, A Genuine Narrative. 
already mentioned a number of publications in which mollies appear as characters, complainants, or criminals, but what kind of textual afterlives might they have secured beyond this? Is there a canon, or multiple canons, of molly literature, whose secrecy and humor would have strengthened their community ties while offering them visibility, in spite of its gaps and omissions? Such canons would have been driven by the molly language as an emblem of cultural belonging and productive queer obscurity.

There are at least two surviving texts which qualify as "molly canon," and which are bound up with their culture. In 1723, an anonymous writer known as "A Moore" - amour - published a remarkable text called Love Letters between a Certain Late Nobleman and the Famous Mr. Wilson. ${ }^{24}$ This manufactured correspondence details an erotic relationship between the unknown nobleman and Edward Wilson, a young social climber who was killed in duel in 1694 . Although the letters are fabricated, they tell us a great deal about what Randolph Trumbach calls the "sodomitical subcultures" of the long eighteenth century. ${ }^{25}$ In the first printed letter, the nobleman wonders at Wilson's "cold insensibility," before suggesting a late-night rendezvous in Greenwich Park. Wilson's reply is coy: “Tho' I'm not afraid to meet a brave Man's Sword, the Indearments of a fine Lady are infinitely preferable." 26 The text begins with a libertine bisexuality that had already become obsolete, and rapidly transitions to a new relationship model that flirts with equality.

There are several costume changes, and a thrilling escape involving Wilson in full drag, all of which would have appealed to molly readers. Wilson, the nobleman, and an equally mysterious noblewoman named Lady V all send messages to each other via "engines," the sort of runners or "culls" that mollies employed themselves. When the nobleman suspects Wilson of infidelity, his anger disrupts the very margins of the letter:

24. Michael S. Kimmel, Ed. Love Letters between a Certain Late Nobleman and the Famous Mr. Wilson (New York: Harrington Park Press, 1990), 30.

25. Randolph Trumbach, "Sodomitical Subcultures, Sodomitical Roles, and the Gender Revolution of the Eighteenth Century: The Recent Historiography" in 'Tis Nature's Fault: Unauthorized Sexuality during the Enlightenment, ed. Robert MacCubbin (Cambridge, UK: Cambridge University, 1988), 109-21.

26. Love Letters, 16. 
It seems I have taught you a Trade, and Harlot-like you intend to be as common and as despicable as those abject Wretches [We must beg Pardon of the Reader for omitting here some Lines which are in the Original of this Letter, being too obscene to be inserted].

If the mollies are, ironically, the "wretches," their culture remains tantalizingly sotto voce. This narrative disruption is similar to a moment in James Dalton's Genuine Narrative, in which Dalton is unable to articulate what he learns about molly culture: "The Relation exceeds all Bounds of Modesty, and is too shocking to appear in publick." ${ }^{27}$ Part of the play of these texts involves the unspeakability of the mollies, the way in which their sexuality contaminates written discourse, even as they remain defiant textual objects. Wilson's reply to the nobleman is both instructive and unexpected: "Am I not the Creature of your Framing," he demands, "to rise, to fall, to live or die, to mould and fashion as you please?” Creature is also a canting term: Bailey's 1737 dictionary defines creatures as "men raised by others, and their Tools ever after." ${ }^{28}$ The letters make use of slang that was circulating in the molly world.

A second popular text, germane to this subcultural readership, is A Spy on Mother Midnight, published serially in 1748 (the exact year in which Love Letters was reprinted). ${ }^{29}$ Mother Midnight is canting slang for a midwife who works as a bawd. The term appears as early as 1699, which marked the beginning of organized hostility against the mollies. This three-part text details the cross-dressing adventures of a bisexual protagonist, who wears petticoats in order to seduce women. His plan is to infiltrate the lying-in chamber, but he ends up at a seedy inn run by Mother Midnight, which resembles a molly house in almost every way. Together with the women (some of whom are men), the protagonist performs a play that includes a character named Sukey. Laura Thomason argues that "Mother Midnight's libertinism creates homoerotic allure without the intratextual or actual punishment expected in connection with both pornography and homosexuality." ${ }^{30}$ In one

27. Dalton, A Genuine Narrative, 36.

28. Nathan Bailey, A New Canting Dictionary. 1737. 18th Century and Regency Thieves' Cant. http://www.pascalbonenfant.com/18c/cant/

29. A Spy on Mother Midnight. 1748. Eighteenth Century Collections Online.

30. Laura Thomason, "The Covert Homoeroticism of A Spy on Mother Midnight," The Eighteenth Century 50, no. 4 (2010): 271. 
scene, the protagonist loses his petticoat when he falls off a horse, revealing himself to a male suitor:

[I] left my Lover a full View of the Land of Promise... I should not have betrayed the Secret if I could help it, but since it happen'd that my Booby saw it, much Good may it do him. I'm sure he has been heartily roasted about it, and his Behaviour; for I did not conceal one Tittle of it from those we went to see. ${ }^{31}$

Not only does the protagonist feel no worry at being discovered - on the contrary, discovery is the point - he also gossips about the encounter later. Tittle, another canting word, refers to both gossip and the loose-tongued speaker. Though the very purpose of a canting language is to speak freely while avoiding discovery, it becomes clear while reading these texts that slang can also be structured to make one visible. At the end of the first volume, the protagonist boldly announces to his friend - the target of his letters - that "I must acquaint you, that I am still in Petticoats, and have had more than one Affair with the Females of this Part of the World; nay, and have done some Execution among those of my own Sex." 32 Why must his reader be acquainted with a fact that would surely place them both in jeopardy? If the text itself was designed for those connected to molly culture, then this announcement would offer both a private jest and a public spark of hope.

Elizabeth Savage identifies Mother Midnight as a nostalgic text: "[The protagonist's] sexual exploits are located firmly within an older world of freewheeling libertine excess, while his ability to effectively dominate the men and women in his changing world are sharply limited." 33 Much like Love Letters, it attempts to address the transition from a libertine model to an urban sexual subculture based more firmly on identity politics. But this three-volume text also focuses on community and shared vocabulary in a way that belies any affection for the disorganized tradition of libertinism. The playacting in the first volume appears to reconstruct the playful yet dangerous environment of an eighteenth-century molly house, where drag is both a cipher and

31. A Continuation of Mr. F--'s Adventures in Petty-Coats. 1748. Eighteenth Century Collections Online, 35-36.

32. A Spy on Mother Midnight. 1748 Eighteenth Century Collections Online, 36.

33. Elizabeth Savage, "Phallic Nationalism: Limits of Male Homosocial Desire in A Spy on Mother Midnight," Genders 56 (Fall 2012). 
a way of life, a visible canting that mingles the art of passing with a raucous, musical claim to subjectivity. The author presumes that the readers are familiar with musicals like The Beggar's Opera, as well as satires on midwifery and "lying-in" as a type of performance. The mollies reading this text would be conversant with literature and theatre, analysis and tiring-room bawdy, delectation and street cant within "that dear market of pleasure London." ${ }^{4}$ This produces a horizon in which the mollies, rather than fleeing persecution, are actors in a play of urban secrecy and pleasure. They become the heroes of their own queer text.

Much criticism has focused on the mollies as a subcultural phenomenon, bounded in nature, described by others but rarely speaking for themselves. While critics often mention the relationship between molly slang and criminal cant, they rarely devote a great deal of attention to the complexity of these linguistic relationships, which were delicately braided and reached across classes and neighborhoods in eighteenth-century London. This discussion has aimed at teasing out some of these relationships, while exploring the ways in which the mollies developed a working language whose foundations remain visible today. Rather than simply borrowing cant terms from the criminal underworld, they shared in a flowering of subcultural languages that were trying to de-centre a monolithic English, a mother-tongue currently being codified in popular dictionaries. We cannot simply observe that terms like molly transitioned from defining female sex-work ("Moll") to defining male homosexuality ("So, Molly"). These rich terms had multiple meanings dependent upon context, and the mollies carved out useful space within the gaps - they owned and refashioned the language, rather than having it inflicted upon them. Linguistic associations with criminal cant expose an overlapping society whose complexity cannot be overestimated. They were not uneasy neighbors, but intimate survivors, often pitted against each other by the forces that sought their erasure. They "baffled" evidence against each other, bailed each other out, crafting language as defense and affiliation.

Stephen Shapiro has argued that molly slang was not confined to the underworld: "[Verbs like] '[c]hapel' and 'marry' are printer artisan

34. A Further Continuation of Mr. F--'s Adventures in Petty-Coats. 1748. Eighteenth Century Collections Online, 17. 
slang for the workplace and its activities. As one of the most downwardly mobile groups, printers would congregate in the same regions as the molly houses such as Grub Street." ${ }^{35}$ Shapiro is the only critic that I have encountered who mentions this connection, which suggests that the breadth of molly slang is likely more far-reaching than we have properly understood. It emerges not just explicitly from criminal communities, but from a variety of marginalized communities who found it beneficial to adopt slang. This reflects a changing London, where immigration was producing a continuum of "Englishes," from Cockney to cant. Shapiros point illustrates my own connection between the mollies and print culture. If some of their terms were influenced by printers, then it becomes all the more important to view their language as a fusion of oral and written text. Print publications such as A Spy on Mother Midnight and Love Letters would have offered them a glimpse of their own spoken lives, their own verbal games and complications, in a hostile world that was interested more in their uncanny speech than in their survival.

The force of this language survives today, though we rarely attempt to trace its entangled origins. Polari terms such as "vada voom," "queen,"36 "trade," and "drag" continue to circulate. Backslang such as "riah" (for "hair") appear in recent publications aimed at a broad audience, such as Caitlin Moran's 2012 biography How To Be A Woman. A cursory viewing of RuPaul's Drag Race yields terms which are vital to drag culture, such as "reading" (to insult someone by seeing through them) and "shade" (to craft an insult which exposes someone, like an open book). Coming to queer consciousness in the twenty-first century often involves learning to decode particular terms, from those designed to classify ("LGBTQ") to slang terms like "bear" which denote both a subculture and a shifting physical appearance. These words, belonging to a legacy of linguistic tradition and adaptation, offer us a way to speak our own identities, to conjugate and translate ourselves into a conversation that has never stopped - similar to Kenneth Burke's metaphor of

35. Shapiro, Stephen. "Of Mollies: Class and Same-Sex Sexualities in the Eighteenth Century," in In A Queer Place: Sexuality and Belonging in British and European Contexts. Ed. Kate Chedgzoy, et al. (Hampshire: Ashgate, 2002), 155-76, 163.

36. Queen as a queer term comes from the Middle English "quean," slang for sex-worker. 
discourse as a late-night party without beginning or end, into which you must "dip your oar." This discussion argues that the mollies were doing the same thing. They entered a conversation that involved criminal cant, actor's slang, workplace jargon, and perhaps even linguistic forms as old as Lingua Franca. They defined themselves deliberately through speech as much as through other performances, like drag, which critics have primarily focused upon. This word emerges from a canting term, which attempts to describe the sly drag of a fox's tail on the ground, a gesture of fashion and power that might be shared by both men and women. Literature was not simply mobilized against the mollies, but evolved to accommodate their shared irony and verbal singularity.

This perspective affords us a longer, more complex view of the mollies as a group. Their adaptive language proves that they were not a bounded phenomenon that disappeared, but part of an enduring queer conversation which has continued to this day. In suggesting a molly canon, I want to shift our idea of the mollies away from isolated text in Old Bailey transcripts, and reposition them as lively speakers and readers. Though existing criticism has cited their use of dialect, and the ambiguous ways in which they appeared textually, my goal is to examine the myriad ways in which these practices were connected. Molly slang was not merely an act of verbal secrecy, but a sophisticated oral tradition which was eventually adapted in print. The fact that we continue to use fragments of molly cant today reinforces the significance of language to this historical community, which existed at a time when "private" and "public" were being redefined by trials, voting reforms, and the spaces of urban London itself. What crystallizes is a durable culture of queer people who found shelter and power within their own language, and who participated in overlapping linguistic communities. They spoke, read, and sang themselves into being during dark times, and their voices continue to resonate in contemporary queer language. 